petent anatomists that the parovarium and paroöphoron represent, in the female, the vasa efferentia and paradidymis of the male. Now the anterior tubules of the parovarium, known as Kobelt's tubes, give rise to small pedunculated cysts hanging from the broad ligament in every way resembling " so-called supernumerary hydatids of Morgagni " in the male ; whilst the sessile cysts which burrow between the layers of the broad ligament, known as parovarian cysts, arise in the tubules which in the male give rise to encysted hydrocele of the testis. In a few words, encysted hydrocele of the testis and parovarian cysts are homologous. The pathological homology of the paradidymis and paroöphoron comes out in another way. The venous network known as the pampiniform plexus arises mainly in these degenerate remnants of the mesonephros; indeed, they are the persistent portions of the veins which, in the early embryo, conveyed the blood from the mesonephroi to the cardinal veins. Thus varicocele in the female and male is morphologically, as well as pathologically, homologous.

We may now consider some important observations made by Pozzi relative to the parts in the male homologous with the hymen in the female. These views may be summarised thus: Often in the female child, and occasionally in the adult female, we find running downwards from the clitoris a band of fibrous tissue which divides, surrounds the meatus urinarius, and becomes continuous with the hymen. This is the vestibular band. In a male the subject of hypospadias this vestibular band was found by Pozzi to be extremely well marked and to replace the corpus spongiosum penis. From this and some similar specimens he comes to the opinion that the hymen in the female is homologous with the bulb in the male. My own dissections of hermaphrodites do not lead me to concur with this conclusion. If this view be correct we ought to test it in a critical manner thus: If the bulb in the male is homologous with the hymen, we ought in some cases of imperforate urethra in the male to find the obstruction situated at or in the immediate neighbourhood of the bulb. To put it plainly: An imperforate hymen in the male should obstruct the urethra, and such an obstruction should be situated anterior to the sinus pocularis. At present I have had no opportunity of testing this critically, but in cases of males furnished with a uterus and vagina the latter has communicated with the urethra by way of the sinus pocularis. Shattock has recently pointed out that if the hymen is represented in the male it ought to be found at the spot where the sinus pocularis opens into the prostatic urethra, for this is the point where the confluent Müller's ducts, which form the vagina, open into the cloaca, and the sinus pocularis is regarded by morphologists as the representative of the vagina in the male. As a matter of fact a hymen occasionally occurs in this situation. Sometimes it is imperforate, and when associated with a uterus in the male will lead to its conversion into a retention cyst. Thus, according to Shattock, the hymen is formed from the anterior wall of the cloaca, and not from the proctodœum.

\section{THE TREATMENT OF INCOMPLETELY DESCENDED TESTICLE.}

By W. WATSON CHEYNE, M.B., F.R.C.S.,

Surgeon to King's College Hospital, and the Paddington Green Children's Hospital, etc.

ON account of the grave inconveniences which attend the retention of testicles in the inguinal canal, I have, like a good many other surgeons, made attempts in several cases to bring them down into their proper position in the scrotum, but I cannot say that the results of these attempts have been very brilliant. The following case, however, in which I adopted a new method, and in which the result was practically perfect, may be of interest. I may say that I have tried most of the plans suggested, and have in all cases, after freeing the cord and testicle, stitched the latter to the lowest part of the scrotum by means of catgut, and afterwards placed catgut sutures in the external ring to prevent the testicle slipping up again into the inguinal canal. The immediate result is that as soon as the hold on the testicle is relaxed, it retracts to the external ring, drawing in the scrotum with it, thus forming a pucker, and the ultimate result is that the testicle lies at, or very little below, the external ring, in a position very little better than that which it formerly occupied. It struck me, however, that if we could keep up the tension on the cord for some days it would gradually stretch, and that then, when the tension was relaxed, the testicle would remain in its new position in the scrotum. The accompanying drawing will show the mode in which this object was attained in the case which $I$ am about to relate.

I had a small triangular wire frame constructed which fitted into the perineum and over the pubes in the manner shown in the accompanying drawing, and was kept in its place by threads of carbolised silk, attached to each angle of the frame and passed round the abdomen and thighs. At a point opposite the apex of the scrotum a projecting bar was attached to the frame to which the thread which passed through the cord could be tied. The mode of operation in this case was as follows: The testicle and cord were freed and brought down into the scrotum, in which a pouch was formed for its reception. A strong catgut stitch was then passed through the structures of the cord immediately above the testicle, and both ends were brought out through a hole at the apex of the scrotum and tied around the projecting bar. Care was taken that the vas deferens should not be on the side of the cord through which the thread might cut its way. In this way any desired amount of tension can be kept up on the cord, and in this particular case I did not stretch the cord at the time of the operation as completely as I intended ultimately to do, but tightened it at the second dressing some days later. After stitching up the external ring and the wound, the whole arrangement was enveloped in antiseptic dressings. I did not in this case pass the

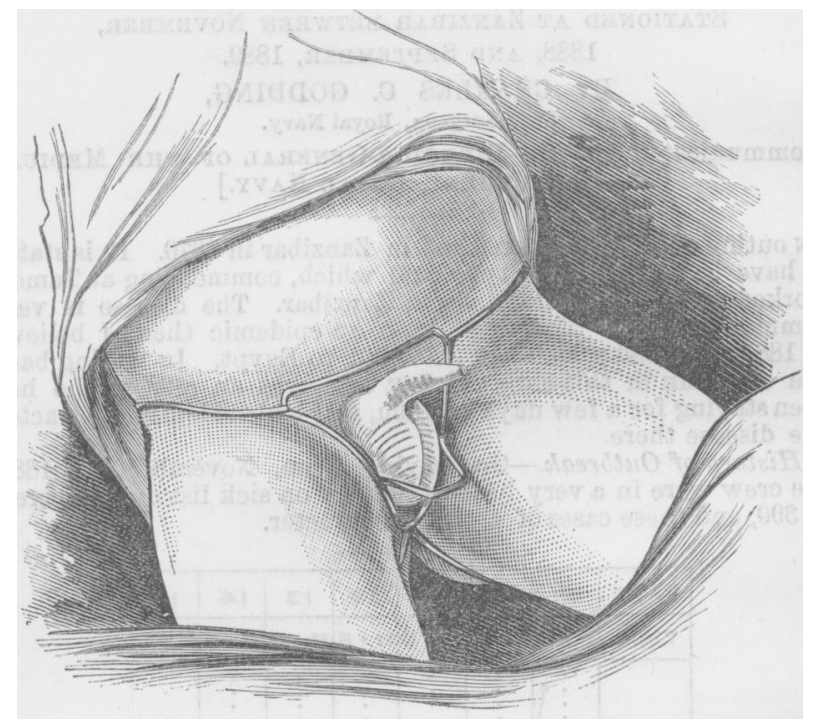

stitch through the apex of the testicle but through the cord, because I did not wish to set up orchitis, nor to destroy any of the testicular structure, while I thought the stitch would not cut through the cord so quickly as through the testicle.

of course it is only in a certain proportion of these cases that any operation with the view of bringing down the testicle can be of benefit, and I should only attempt it in cases where the testicle was fairly movable in the inguinal canal and could be readily made to protrude at the external ring. Where the testicle is retained at the upper part of the inguinal canal, the cord very short and the testicle much atrophied, I believe it is best, in view of the serious trouble to which it may afterwards give rise, to excise it at once and bring together the walls of the inguinal canal. The following is the case to which I allude.

H. E., aged 11, was admitted into the Paddington Green Children's Hospital on February $27 \mathrm{th}, 1889$. Both testicles were lying at the lower part of the inguinal canal, and could be readily made to protrude at the external ring; they had been in this position since birth.

On March 1st I operated on the right side, but I did not employ the plan above described. In order to carry out the same prin- 
ciple, however, after stitching the testicle to the bottom of the scrotum, and while the assiscant held it in that position, I passed a catgut stitch through the skin at the junction of the scrotum and thigh, through the cord just below the external ring and through the skin on the other side of the scrotum, with the view of, so to speak, anchoring the testicle in the scrotum. The wound healed by first intention, but the ultimate result has been that though the testicle is considerably below the external ring, it is not in its proper position in the scrotum.

Before operating on the left side, I therefore had the wire frame described above constructed, and on April 2nd I operated on the left side in the manner which I have mentioned. The dressing was changed next day, and everything was looking well; patient comfortable. It was again changed on the $6 \mathrm{th}$, and the catgut tightened as much as possible; the wound had healed. On the 13th the stitch was removed, the apparatus left off, and a small collodion dressing was fixed over the puncture through which the stitch had passed. The testicle hardly receded at all when the stitch was divided, and there was a good deal of thickening about the cord and the external ring, which no doubt helped to keep things in position. The patient was allowed to get up on the 15th, and went home on April 22nd. He was exhibited at the Medical Society about ten months later, when the left testicle occupied its normal position in the scrotum.

\section{AN ACCOUNT OF}

\section{AN OBSCURE OUTBREAK OF DENGUE}

OCCURRING ON BOARd H.M.S. AGAMEMNON WHILE

STATIONED at ZaNzibar Betwein NOVEMBer, 1888, AND SePTEMBER, 1889.

Br CHARLES C. GODDING, Staff-Surgeon, Royal Navy.

Communicated by the Director-General of the Medical Departakent, Royal NaVY.]

$\Delta \mathrm{w}$ outbreak of dengue occurred in Zanzibar in 1870 . It is stated to have been of a severe type, and which, commencing at Tamoo, worked south to Mombassa and Zanzibar. The disease is very common at Aden. There had been an epidemic there, I believe, in 1887-1888, and which had extended to Egypt. In tracing back the outbreak in this ship, the first cass was an officer who had been staying for a few days at Aden, and had evidently contracted the disease there.

History of Outbreak.-On leaving Aden, November 1st, 1888, the crew were in a very healthy state, 8 on sick list out of a crew of 390 , and these cases of a trivial character.

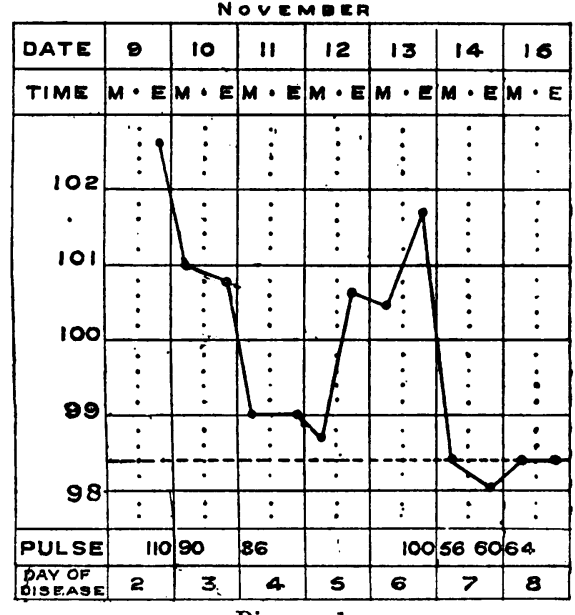

Diagram 1.

On November 9th, Commander M., officer taking passage and referred to above, came under treatment. Stated that on November 3rd he had suffered from aching pains in his legs, and had been poorly since.

On evening of 8 th he felt. restless all night, but this morning (9th) he had bad headache, nausea, malaise, and severo pains on inner side of thighs; constipation.

November 10th. Rigors last evening, followed by profuse sweating during the night; pains between shoulders, tongue white, and conjunctivæ yellowish.

November 11th. Feels much better, but there is still some nauses and headache. The general muscular pains have gone; tongue cleaning; profuse sweating all night.

November 12th. Much better in the morning, but during the afternoon severe headache returned, with much weakness and malaise.

November 13th. Severe headache; face flushed; anorexia; general pains, debility, and malaise; bowels constipated. Left this ship at 5 P.M. On November 14th, skin moist, tongue slightly creamy ; slept well and convalesced quickly, and returned to duty on November 21st. (See Diagram 1.)

This case was the first of its kind, and typical of all the cases which followed, both in symptoms and temperature. Attention was only called to it in tracing back the disease to its origin, and, at the time of its occurrence, it was diagnosed as a severe case of simple continued fever. In one or two doubtful cases a fleeting blush followed profuse sweating; but, until July 8th, 1889, a period of seven months, no case with an unmistakable rash had appeared, though during this period 118 cases and 57 milder cases had occurred. The 118 cases were diagnosed as a severe form of simple continued fever, closely resembling dengue, peculiar to the station, and the thermometry of which had not been described, while the 57 milder cases were diagnosed as ordinary cases of febricula. The cases were all characterised by sudden onset. intense frontal headache, giddiness and great heaviness, retching and bilious vomiting, conjunctivæ yellowish, bowels frequently purged but sometimes constipated, marked anorexia, tongue yellow and coated, rigors and severe aching pains about body and loins. Partial defervescence and comparative comfort on third and fourth days, then considerable increase of fever to fastigium and defervescence by crisis with profuse sweating, which continued for two or three days in decreasing quantities. Great debility followed, and relapses in several cases.

Difficulty of Diagnosis.-A similar type of disease is very common on the East Indies Station. In 1885, H.M.S. Dragon had 128 cases (simple continued fever) out of a crew of 156, the bulk of the cases occurring in April and May; average 4.5 days' sickness. H.M.S. Turquoise, 75 cases; average 7.5 days' sickness. H.M.S. Briton, 65 cases; average, a little over 7 days' sickness. In the cases occurring in the Agamemnon, though many of the symptoms closely resembled those of dengue, there was a complete absence of eruption, no pain and swellings of joints, no patient convalescing for a few days and then having a true relapse, nor did the disease assume a decidedly epidemic character till the end of June, when the cases occurred in batches with precisely the same general symptoms, but more severe lumbar pains. Symptoms were grouped as follows:-1. Sudden onset, severe headache, generally frontal; bad pains in loins, malaise, fever and characteristic yellow tongue. 2. Diminution of fever and comparative comfort for two days. 3. Increase of fever, headache. lumbar and general muscular pains, with fall of temperature by crisis and profuse sweats. 4. Convalescence rapid, but marked by considerable debility. 5. Temperature charts closely resemble the one already given. Sudden rise, considerable fall on third and fourth days, then a rise to the fastigium and descent by crisis; the symptoms accompanying the second rise were always severe, the headache, pains, malaise, and mental depression returning in a most trying manner.

This descent of temperature by crisis was not universal. In a few cases the descent was by lysis, and this generally occurred in the most severe cases with long convalescence.

November 16th, 1887. Dr. F. M. Sandwith gives Diagram 2 as \& chart of a typical case in outbreak in Egypt:-Eruption : measly eruption afternoon of 18 th, third day. Temperatures almost exactly the reverse of the cases occurring in this ship. Pulse bears some resemblance. Convalescence on twentieth day.

July 12th, 1889. Diagram 3 is typical of most of the cases having an eruption in this ship. Patient had also swelling of parotids, and slight salivation. Eruption : mixed, scarlatinal, and finely papular on morning of third day, and faded on sixth day. Temperature and pulse bearing close resemblance to the first case which occurred on board. Convalescence on eighth day. Duty on twelfth day. 